\title{
Optimization Letters Best Paper Award
}

\author{
Pavlo Krokhmal $^{1}$ • Oleg A. Prokopyev ${ }^{2}$
}

Received: 18 December 2015 / Accepted: 20 December 2015 / Published online: 5 January 2016

(C) Springer-Verlag Berlin Heidelberg 2016

\section{Dear Colleagues:}

It is our pleasure to announce the 2014 OPTL Best Paper Award. A total of 12 papers published in Optimization Letters during the year of 2014 were nominated for the Award and considered by the Best Paper Award Committee, which included OPTL Editorial Board members Dr. Immanuel Bomze, Dr. Jean-Philippe P. Richard, and the Founding Editor-In-Chief, Dr. Panos M. Pardalos. Based on the recommendations of the Committee, the following paper was named the winner of the 2014 OPTL Best Paper Award:

Petter Brändén (2014) Hyperbolicity cones of elementary symmetric polynomials are spectrahedral, Optimization Letters 8(5), 1773-1782.

The OPTL Best Paper Award carries a 1,000 USD prize and a plaque. Please join us in congratulating Dr. Brändén for his excellent contribution to literature!

We want to thank the members of the Committee for their service and Springer for sponsoring the award. We also would like to take this opportunity to invite nominations for the 2015 OPTL Best Paper Award. All papers published in OPTL during the year of 2015 are eligible.

Oleg A. Prokopyev

droleg@pitt.edu

1 Department of Systems and Industrial Engineering, University of Arizona, Tucson, AZ 85721-0020, USA

2 Department of Industrial Engineering, University of Pittsburgh, Pittsburgh, PA 15261, USA 